\title{
A personal view on drugs in sport
}

\author{
Roger G. Hackney, MB, Dip Sports Med \\ Olympic 3000 metre steeplechaser \\ Assistant Honorary Secretary, B.A.S.M.
}

Sports medicine has received a great deal of publicity recently. The discovery that the fastest man ever over 100 metres, the world and Olympic champion, had only achieved those heights by cheating, shocked the world. The Canadian inquiry revelations claim that most athletes in Seoul were also taking steroids. One of the justifications of those who abuse drugs is that everyone else is doing it and all they are doing is keeping up with the rest. Some claim that the reason we are seeing so much steroid use is that there is so much money in sport now. It would be naive to say that it plays no part, but anabolic steroids were being used long before athletics became a big money sport, and some of those pointing the finger at money, have done very nicely from sport themselves.

We have long suspected the East Europeans of achieving their success by sports pharmacology, but there are said to be changes in progress with glasnost. Athletes from the USA, West Germany, Finland, even Belgium have all been caught using steroids. The book written by David Jenkins, not publishable in the UK is alleged to name names of officials and athletes. It is very difficult to even guess at how many athletes in the UK abuse steroids. As one Canadian who confessed said 'If this hadn't come out, then we would have died without even telling our mothers'. I like to think that our medal winners in the middle distances at least, are scrupulously clean. The British Amateur Athletic Board have out-of-season testing as a deterrent. At long last the International Amateur Athletic Federation are planning the same thing.

The objectives of training season testing are excellent. To be credible however, the testers need to be fully independent. In the past, National Federations have been implicated in collusion, or even organisation of drug use. To give these bodies the task of catching their proteges is ludicrous. It only needs one official to tip off the guilty athlete and for him or her to suddenly depart the training venue the day before the testers arrive for the system to fail.

I would like to see a totally independent body set up with the ability to test any international standard athlete any time, any where in the world.

A lot of pre-Olympic press reports concerned the injuries of some of our Seoul medal hopefuls. At high level sport there is a very fine line drawn between getting preparation just right and over-training with breakdown. As I know only too well, it is easy to step over that line. What concerned me, was that so many

Flight Lieutenant R.G. Hackney,

clo RAF Hospital, Halton, Wendover, Bucks, UK.

(C) 1989 Butterworth \& Co (Publishers) Ltd 0306-3674/89/020080-01 \$03.00 of the press reports were of sportsmen and women travelling to West Germany or Scandinavia to seek medical help. There was obvious implied criticism of the facilities in the UK in many of the newspaper articles I read. Yet as an aspiring orthopaedic surgeon I know that there is great expertise available in this country. Having met several of those who travelled abroad to seek help, I know there was nothing remarkable in either their condition or, in most cases, the treatment received. Some were, in my opinion, the victims of pseudo-science.

Two questions arise. First, why do these athletes feel it necessary to go to the continent? Secondly, what can we, the umbrella organization for sports medicine in the UK, do about it? The reasons given to me for going abroad include delay in being seen at home; an unsympathetic 'take it or leave it' attitude; and of simply not knowing how to get to see someone with an interest in their problem.

Who should be responsible for ensuring that sportsmen and women have speedy access to help that is both expert and interested? Some governing bodies take reasonable measures to look after their elite. The International Athletes' Club have a private health insurance scheme for the top performers in each event. The National Health Service does not appear to be the answer for sportsmen, and the current political traumas will not improve morale and time available to treat sports injuries. Enthusiastic individuals scattered about the nation exist, but one of the questions other athletes constantly ask me is why there isn't a list of 'good' people they can consult.

Sports medicine in this country has always struck me as being little more than a disparate group of interested individuals and organizations without leadership or clear direction.

BASM is in the position of being recognized by the Sports Council as the body responsible for sports medicine in the UK, for elite and casual athletes alike. BASM needs funding. We should be pointing out to the government via the Sports Council that improving the general health of the population with a 'Sport for All' programme, and thereby gaining economically, is bound to lead to increased demand for treatment of sports injuries. Money will enable BASM to expand its educational programme. Improving knowledge at primary care level has got to be a major effort. The new Diploma from the Society of Apothecaries, together with the London Hospital Diploma should be a basic requirement for any doctor wanting to run a clinic. There are problems to overcome, but the committee is collating a list of sports injury clinics. The band-wagon of sports injuries clinics is rolling. The field must not be left to those whose motives are purely financial, to the detriment of athletes of all standards. 